\title{
Green Product Design with Competition and Fairness Concerns in the \\ Circular Economy Era
}

\author{
Qingying Li* \\ liqingying@dhu.edu.cn \\ Glorious Sun School of Business and Management, Donghua University, Shanghai, China \\ Xiaotong Guan \\ guanxiaotong17@163.com \\ Glorious Sun School of Business and Management, Donghua University, Shanghai, China \\ Tianqin Shi \\ tianqin.shi@sjsu.edu \\ Lucas College and Graduate School of Business, San José State University, San Jose, USA \\ Wen Jiao \\ w.jiao@lboro.ac.uk \\ School of Business and Economics, Loughborough University, Loughborough, UK
}

\begin{abstract}
In this paper, we consider green product design in a supply chain consisting of one manufacturer and two retailers, where retailer 1 aims at monetary profit maximization, and retailer 2 has fairness concern. We consider two kinds of green products: a marginal-intensive green product (MIGP) and a development-intensive green product (DIGP). For the former, the green investment cost depends on the green level and the production quantity; while for the latter, the green investment cost depends on the green level solely. In each case, we investigate the impact of the retailer's fairness concern by comparing the optimal solutions and supply chain performance with those in the basic models in which all the supply chain members aim at profit maximization. We find that retailer 2 will set a higher retailing price and earn a smaller market share. Such inferiority increases as retailer 2's inequity aversion increases or as the substitutability degree of the products offered by the two retailers increases. We also find that retailer 2's fairness concern will always harm the manufacturer. If an equity outcome is achieved, the supply chain may achieve a better performance; however, if an inequity outcome is attained, the supply chain always performs worse.
\end{abstract}


Keywords: green product design, fairness concern, retailing competition, circular economy

\section{Introduction}

The circular economy aims to eliminate waste and can potentially generate a net benefit of US\$2.0 trillion in Europe and US\$4.5 trillion worldwide by 2030 (Ellen MacArthur Foundation 2015, Lacy and Rutqvist 2015). The era of circular economy has witnessed the enactment of stricter environmental regulations around the globe. Environmental laws such as The Waste Electrical and Electronic Equipment Directives require that the rate of recovery by an average weight per appliance be increased to a minimum of $70-80 \%$ by 2006 and $75-85 \%$ by 2018 (WEEE Directive 2002, 2012). The EU emissions trading system set Phase 3's starting an overall number of allowances ("cap") to be 16.5\% below verified 2005 emissions, with an annual decline rate of $1.74 \%$ in $2013-2020$ and an annual decline rate of $2.2 \%$ in $2021-2030$ (EU ETS 2017). Meanwhile, consumers have become more environmentally conscious and have adopted more sustainable behaviors in the circular economy era. According to a survey conducted in 60 countries by Nielsen (2015), 66\% of 30,000 consumers are willing to pay more for sustainable brands, up from 55\% in 2014 and 50\% in 2013. In fact, in the retail market, consumers are willing to pay up to a $25 \%$ premium for sustainable offerings (Du et al. 2017).

In order to meet regulatory requirements and customer expectations, a growing number of manufacturers and retailers have been striving towards a circular economy by dedicating a significant amount of investments to designing, making and promoting green products. A CEO study by United Nations Global Compact and Accenture revealed that $91 \%$ of 766 CEOs from nearly 100 countries believed that their company would employ new technologies such as renewable energy and information and communication technologies to address environmental issues over the next five years (UN Global Compact and Accenture, 2010). In reality, companies such as General Electric, Apple, and Microsoft have launched various programs to reduce toxins, greenhouse emissions, and energy consumptions from their products (Dey et al. 2019). Benefiting from green orientations in terms of increased financial gains, market share, levels of employee commitment, customer satisfaction, and firm valuations (Gleim et al. 2013), more and more producers are actively collaborating with distributors and retailers in improving 
the environmental performance of their end-to-end supply chain. Consumers also believe that retailers should promote green products by increasing their visibility on store shelves or by having a green corner dedicated to eco-friendly products (Eurobarometer 2009). As a response to manufacturers and customers' needs, Walmart, the world's biggest retail company, launched the Sustainable Chemistry Initiative to reformulate over 125,000 personal care, beauty, baby, pet, household cleaning, apparel, footwear and soft home textile products based on the 12 Principles of Green Chemistry (Walmart 2019). Such initiatives design out "waste" and eliminate negative externality as defined in the circular economy (Ellen MacArthur Foundation, 2015).

Nevertheless, when facing increased wholesale prices and uncertain demand as a result of a greener product design or initiative by the producer, a fair-minded retailer may perceive that its profit margin is unfairly squeezed and thus reacts unfavorably towards the manufacturer $(\mathrm{Li}$ et al. 2018). Fairness concern, defined as fairness preference by the channel members due to inequality aversion, can affect channel relationships. For example, perceiving unfair pricing and profit benefit allocation, Langsha Knitting, the world's largest hosiery enterprise, terminated cooperation with Walmart in 2007, while Xuzhou Wanji Trading Co., a formerly important distributor of Procter \& Gamble $(\mathrm{P} \& \mathrm{G})$ in China, ended the business relationship with P\&G in 2010 (Nie and Du, 2017). Therefore, in order to achieve a more sustainable supply chain performance, a producer shall take into account its retailers' fairness concerns when adding environmental dimension to its product.

Regarding the studies about circular economy issues, some existing studies have investigated the investment effort with fairness concerns (see, for example, Du et al. 2017, Li et al., 2018, and Zhang et al., 2019). However, the joint effect of horizontal competition and distributional fairness concerns has not been well explored in the literature. Therefore, in this article, we will fill the research gap by focusing on products' green investment. We address the following research questions:

- In a supply chain with green investment and retailing competition, how would the supply chain members, including both a horizontal competitor and an upstream collaborator, respond to a downstream retailer's fairness concern?

- How would the fairness concern affect the profit distribution between the fair-minded 
retailer and the horizontal competitor? What are the impacts of retailing competition intensity and inequity aversion on the profit distribution?

- What is the impact of the fairness concern on the green investment decisions? Would the retailer's emotional concern harm or benefit the entire supply chain?

To answer these questions, we develop and study a supply chain with two competing retailers sourcing from one manufacturer, where retailer 1 is a profit maximizer and retailer 2 has inequity aversion. We consider two types of green products: marginal-intensive green products (MIGPs) of which the total investment cost depends on the production quantity, and development-intensive green products (DIGPs) of which the total investment cost depends solely on the green level. We derive the retailers' optimal retailing prices and the manufacturer's optimal green investment and wholesale price decisions. We also compare the optimal solutions and the supply chain members' profits with those in the basic model where retailer 2 does not have emotional inequity concern, to investigate the effects of the retailer 2's fairness concern.

We find that, in response to retailer 2's fairness concern, the manufacturer will lower the wholesale price and sacrifice some profit while retailer 1 will decrease the retailing price in order to earn a market share no smaller than retailer 2 . The manufacturer will also decrease the green level only with DIGPs. We also find that retailer 2' fairness concern benefits his horizontal competitor in the case with MIGPs, but not necessarily in the case with DIGPs. With both types of green products, if retailer 2 can achieve an equity outcome, the supply chain's performance can improve; however, if retailer 2 can achieve an inequity outcome, the supply chain will always perform worse.

Our paper is organized as follows. In Section 2, we first review the related literature. In Section 3, we develop the decision models of supply chain members. In Sections 4 and 5, we derive the optimal solutions for the MIGP case and the DIGP case, respectively. Section 6 concludes the paper. All the proofs are relegated to the Appendix.

\section{Literature Review}

There are two main streams of related literature: supply chain management regarding green product design, and the operations management with fairness concerns. We next review these 
two streams of literature, respectively.

This work first belongs to the scope of circular economy and sustainable supply chain management, which has received extensive attention in the literature. We refer to Alzaman (2014), Centobelli et al. (2018), and Govindan and Hasanagic (2018) for general reviews in this area. This paper investigates a specific aspect of sustainable operations, namely, green investment, with the consideration of consumer environmental awareness. Ghosh and Shah (2012) consider the bargaining issues in green supply chains. Chen et al. (2017a) and Hong et al. (2019) analyze the impact of supply chain power structures. Ghosh and Shah (2015) and Raj et al. (2018) investigate the supply chain coordination under different contracts. Dong et al. (2016), Xu et al. (2017), and Shi et al. (2018) examine the carbon emission issues in green supply chains. All the above-mentioned studies consider DIGPs; that is, the green investment cost depends on the green level but is independent of the production quantity. In this paper, we consider both MIGPs and DIGPs. For the former MIGPs, the green investment cost depends on the production quantity. Dey et al. (2019) discuss the effects of strategic inventory on a twoperiod supply chain, and both types of green products (MIGP and DIGP) are considered.

The above studies consider a supply chain with one manufacturer and one retailer. In our paper, we explore one manufacturer which trades with two retailers. Zhu and He (2017) investigate the green product design under either retailing competition or supply chain competition by considering both MIGPs and DIGPs. The supply chain's green investment decisions are investigated under different supply chain structures. Shi et al. (2019) consider a similar supply chain structure, where the supply chain members can improve product sustainability by investing in clean technology. The investment can reduce the firm's carbon emission tax can improve consumer utility. They compare the optimal decisions under different scenarios where the manufacturer, one manufacturer, or both retailers conduct the investment. Some studies consider one retailer sources from competing manufacturers, e.g., Liu et al. (2012), Giri et al. (2019), Sim et al. (2019). Being different from the above literature, we study green supply chain management by addressing supply chain members' fairness concerns.

The second stream of literature is related to the fairness concerns, which consider either one or some of the supply chain members that not only seek profit but also have inequality aversion. Supply chain members' fairness concerns can be categorized as distributional fairness 
and peer-induced fairness, depending on whether it incurs among vertical supply chain members or horizontal supply chain members (Fehr and Schmidt 1999). Cui et al. (2007) first use the inequality aversion to characterize fairness concerns in vertical supply chains and show that a designed wholesale-price contract can eliminate the double marginalization and achieve coordination. The linear demand setting in Cui et al.'s (2007) is extended to nonlinear ones by Caliskan-Denmirag et al. (2010), and to stochastic demand functions by $\mathrm{Wu}$ and Niederhoff (2014). Du et al. (2014) investigate the effects of fairness concerns with Nash bargaining. Yang et al. (2013) show that when a fair-minded retailer co-operates with the manufacturer to conduct advertising, the double marginalization can be eliminated. Katok et al. (2014) investigate the performance of a wholesale price contract under the case where the retailer's fairness concern is private information. Studies on fairness concerns in vertical supply chains also explore other operational issues such as manufacturer encroachment ( $\mathrm{Li}$ et al. 2016), financing with budget constraint (Chen et al. 2017b), multi-period modularity design (Li 2018), e-commerce supply chain (Wang et al. 2019), and closed-loop supply chain (Ma et al. 2017).

Fairness concerns are also investigated in triadic supply chains where peer-induced fairness concerns may arise together with distributional fairness concerns. Ho et al. (2014) discuss a supply chain with two retailers sourcing from one manufacturer, where the first-moving retailer has a distribution fairness concern with the manufacturer, and the second-moving retailer has both distributional fairness concerns with the manufacturer and peer-induced fairness concerns with the other retailer. It is shown that the second retailer will set a higher price and earn a lower profit than the first one. Nie and Du (2017) extend Ho et al.'s (2014) model by analyzing the effects of quantity-discount contracts on the supply chain coordination. Du et al. (2018) also investigate the same supply chain structure by focusing on the peer-induced fairness concern between the two retailers. In these supply chains, the two retailers operate in separate demand markets and there is no competition between the retailers. In this paper, however, we include the retailer competition in our supply chain and investigate the joint effect of fairness concerns and horizontal competition. To sustain the tractability, we restrict our attention to the distributional fairness concern only. It is worth mentioning that there are some studies on fairness concerns that consider a downstream manufacturer sourcing from two upstream manufacturers; see, e.g., Chen et al. (2015), Liu et al. (2018), Zhang and Wang (2018). 
Our paper is most related to Du et al. (2017), Li et al. (2018), and Zhang et al. (2019), which consider the sustainability investment together with distributional fairness concerns. Du et al. (2017) study the case where both the manufacturer and the retailer invest in green technology innovation development and show that the distributional fairness concerns from either the supply chain members will enhance the technology innovation development. Li et al. (2018) investigate the carbon emission reduction decisions with a fair-minded retailer, where carbon emission reduction can increase the market demand. Zhang et al. (2019) consider the sustainability investment for marginal cost-intensive products, where the investment can improve the demand and reduce the carbon emission cost. These studies focus on the effect of distributional fairness concerns in two-tier supply chains. In our paper, we consider a manufacturer trading with two competing retailers, and we investigate the joint effect of horizontal competition and distributional fairness concerns on the green product investment.

\section{The model}

We consider a supply chain consisting of a manufacturer and two competing retailers. For convenience, we refer to retailer 1 as she and retailer 2 as he. The manufacturer makes the production and sells the products through the two retailers, which bear the products with their own brands. The products from the two retailers are substitutable and competing in the same market. To reduce waste and unlock the value of circular economy, the manufacturer can invest in the green product design. We consider two kinds of green products: a marginal cost-intensive green product (MIGP) and a development-intensive green product (DIGP). Regarding a MIGP, the total investment cost depends on the green level and the production quantity (see Zhu and He 2017). For example, in the automobile industry, replacing an old module by a new green one makes the product be a MIGP; and in the apparel industry, companies such as H\&M and American Apparel are using more sustainable fabric that meets the Better Cotton Standard, which are also MIGPs. Regarding a DIGP, the total investment cost solely depends on the green level (see Zhu and He 2017). DIGPs are common for the cases where new technologies need to be significantly developed before being widely adopted in production, e.g., the development of electric car technologies.

Hereafter, we refer to the two cases as the MIGP case and DIGP case, respectively. We 
assume that consumers are environmentally conscious such that investing in green product design can increase consumer demand.

In this paper, we consider the manufacturer as the Stackelberg leader. This is usually the case when the manufacturer gains a higher bargaining power than the retailers or possesses a unique technology or product in a monopolistic market. For example, in the integrated circuit industry, Shin-Etsu, the largest manufacturer of silicon wafer, is considered as a Stackelberg leader that offers a wholesale price to the downstream buyers including TMSC and UMC. This setting is well adopted in the literature, like Nie and Du (2017), Du et al. (2018), and Shi et al. (2019). The event sequence is as follows. Firstly, the Stackelberg manufacturer invests in the green level and determines the wholesale price. We assume the manufacturer offers the same wholesale price to both retailers. Secondly, the retailers observe the manufacturer's decisions and simultaneously determine their retailing prices, respectively. The demand is realized at last.

Follow the common setting in the literature (see, for example, Wang et al. 2016, Zhu and He 2017), we adopt the following demand functions in the competing market with green investment. We assume

$$
D_{i}=a+\gamma e-p_{i}+\theta p_{j}
$$

where $p_{i}$ and $D_{i}$ are the selling price and the realized demand of retailer $i(i, j=1,2, j \neq$ $i), \quad a$ is the market size, $\gamma>0$ is the sensitivity of consumers' environmental awareness, $e$ is the green level that represents the manufacturer's design effort, $\theta$ is the substitutability degree of the two products. Denote $w$ as the manufacturer's wholesale price. The manufacturer's green investment cost depends on the type of the products. We use superscripts " $\mathrm{m}$ " and " $\mathrm{d}$ " to denote the MIGP and DIGP cases, respectively. For $t=m, d$, we let $\Pi_{i}^{t}$ be the manufacturer's profit by selling to retailer $i$, where $i=1,2$, and we let $\Pi^{t}$ be the manufacturer's total profit by selling to both retailers. Thus, $\Pi^{t}=\Pi_{1}^{t}+\Pi_{2}^{t}$. The detailed formulation of $\Pi_{i}^{t}$ and $\Pi^{t}$ will be provided later. Let $\pi_{i}^{t}$ be retailer $i$ 's monetary payoff, $t=m, d$. It is easy to see that $\pi_{i}^{t}$ is independent of the product type and

$$
\pi_{i}^{t}=\left(p_{i}-w\right) D_{i}=\left(p_{i}-w\right)\left(a+\gamma e-p_{i}+\theta p_{j}\right)
$$

where $i, j=1,2, j \neq i$, and $t=m, d$.

One key assumption of this paper is that one retailer is not a pure profit maximizer but, 
instead, has a distributional fairness concern. Without loss of generality, we assume that retailer 1 pursues profit maximization and retailer 2 has a distributional fairness concern. This means that retailer 2 not only cares about his monetary payoff but also has inequity aversion; that is, retailer 2 has an equity belief on his monetary payoff, and he will suffer an emotional disutility if his profit differs from his equity belief (see, e.g., Cui et al. 2007, Li 2018). Thus, inequity aversion includes both disadvantageous inequality (i.e., retailer's profit is less than the equality belief) and advantageous inequality (i.e., retailer's profit is higher than the equality belief). However, according to Rabin (1993), a retailer usually cares about disadvantageous inequality instead of advantageous inequality with the manufacturer being the Stackelberg leader. Therefore, similar to the settings in Ho et al. (2014), and Du et al. (2018), we consider only the disadvantageous inequality in retailer 2's utility. Also, we assume that retailer 2's equality belief on his profit is identical to the manufacturer's monetary payoff from trading with him, i.e., $\Pi_{2}^{t}$. Thus, retailer 2's utility is

$$
U_{2}^{t}=\pi_{2}^{t}-\beta\left(\Pi_{2}^{t}-\pi_{2}^{t}\right)^{+},
$$

where $t=m, d$, and $\beta>0$ is the inequity aversion parameter. The above simplification of retailer 2's equality belief allows us to derive some neat managerial insights. Note also that if “ $\left(\Pi_{2}^{t}-\pi_{2}^{t}\right)^{+}=0$ ", i.e., $U_{2}^{t}=\pi_{2}^{t}$, we say that retailer 2 achieves an equality outcome; that is, retailer 2 does not suffer any emotional disutility. Otherwise, we say retailer 2 attains an inequity outcome.

\section{The MIGP case}

In this section, we consider the MIGP case in which the green investment cost is associated with the production quantity. Following Zhu and He (2017), we let $\xi e^{2}$ be the additional unit production cost with green level $e$, where $\xi>0$. Without loss of generality, we normalize the basic unit production cost to zero. Thus, the manufacturer's profit by selling to retailer $i$ is

$$
\Pi_{i}^{m}=\left(w-\xi e^{2}\right) D_{i}=\left(w-\xi e^{2}\right)\left(a+\gamma e-p_{i}+\theta p_{j}\right),
$$

for $i, j=1,2$, and $i \neq j$, and the manufacturer's total profit is $\Pi^{m}=\Pi_{1}^{m}+\Pi_{2}^{m}$.

We refer to the model where each supply chain member maximizes his/her own profit as the basic model, i.e., the model without fairness concerns. We use the caret " $`$ " to denote the 
optimal solutions in the basic model. Denote $\delta=\frac{\gamma^{2}+4 a \xi(1-\theta)}{\xi}$. Lemma 1 provides the equilibrium solutions to the basic model with MIGPs.

Lemma 1. For the basic model with MIGPs, the optimal decision variables are

$$
\hat{p}_{i}^{m}=\frac{4 a \xi(1-\theta)(3-2 \theta)-\gamma^{2}(7-4 \theta)}{8 \xi(2-\theta)(1-\theta)^{2}}, i=1,2, \quad \widehat{w}^{m}=\frac{3 \gamma^{2}+4 a \xi(1-\theta)}{8 \xi(1-\theta)^{2}}, \text { and } \quad \hat{e}^{m}=\frac{\gamma}{2 \xi(1-\theta)} ;
$$

the supply chain members' profits are

$$
\hat{\pi}_{i}^{m}=\frac{\delta^{2}}{64(2-\theta)^{2}(1-\theta)^{2}}, i=1,2 \text {, and } \widehat{\Pi}^{m}=\frac{\delta^{2}}{32(2-\theta)(1-\theta)^{3}}
$$

and the supply chain's total profit is $\widehat{\Pi}_{S C}^{m}=\frac{\delta^{2}(3-2 \theta)}{32(2-\theta)^{2}(1-\theta)^{3}}$.

According to Lemma 1, the two retailers will set an identical retailing price and each will earn 50 percent share of the market.

In the rest of this section, we will first obtain the retailers' best responses in the retailing prices in Section 4.1, and then analyze the manufacturer's optimal decisions in Section 4.2. We will also conduct the comparison with the results in the basic model in Section 4.3.

\subsection{Retailer's price decisions}

In this subsection, we determine the retailers' price decisions. Recall that retailer 1 maximizes her monetary payoff, and retailer 2 has a distributional fairness concern. From (1)-(3), retailer 1 's monetary payoff is

$$
\pi_{1}^{m}=\left(p_{1}-w\right)\left(a+\gamma e-p_{1}+\theta p_{2}\right)
$$

and retailer 2's utility is

$$
U_{2}^{m}=\left(a+\gamma e-p_{2}+\theta p_{1}\right)\left[p_{2}-w-\beta\left(2 w-p_{2}-\xi e^{2}\right)^{+}\right],
$$

where $a+\gamma e-p_{2}+\theta p_{1}$ is the market demand for retailer 2 and is non-negative. From (4), retailer 2's utility $U_{2}^{m}$ depends on the value of $p_{2}$. Specifically, if $p_{2} \leq 2 w-\xi e^{2}$, then the term in the square brackets can be simplified to $p_{2}-w-\beta\left(2 w-p_{2}-\xi e^{2}\right)$; and if $p_{2}>$ $2 w-\xi e^{2}$, then the term " $\left(2 w-p_{2}-\xi e^{2}\right)^{+}$" equals zero. We show that retailer 2's utility is two-piecewise concave such that the optimal price can be uniquely determined. Recall also that the two retailers make price decisions simultaneously. We summarize the conditionally optimal retailing prices in the following proposition.

Proposition 1. In the MIGP case, given the manufacturer's green level $e$ and the wholesale 
price $w$, the two retailers' optimal retailing prices are given as follows.

$$
p_{1}^{m}(w, e)= \begin{cases}\frac{a+\gamma e+w}{2-\theta}, & \xi e^{2}<w \leq \underline{w}, \\ \frac{a+\gamma e+w+2 \theta w-\theta \xi e^{2}}{2}, & \underline{w}<w<\bar{w}, \\ \frac{a+\gamma e}{2-\theta}+\frac{w(2+2 \beta+\theta+2 \beta \theta)-\theta \beta \xi e^{2}}{(1+\beta)\left(4-\theta^{2}\right)}, & w \geq \bar{w}\end{cases}
$$

and

$$
p_{2}^{m}(w, e)= \begin{cases}\frac{a+\gamma e+w}{2-\theta}, & \xi e^{2}<w \leq \underline{w} \\ 2 w-\xi e^{2}, & \underline{w}<w<\bar{w} \\ \frac{a+\gamma e}{2-\theta}+\frac{w(2+\theta+4 \beta+\theta \beta)-2 \beta \xi e^{2}}{(1+\beta)\left(4-\theta^{2}\right)}, & w \geq \bar{w}\end{cases}
$$

where $\underline{w}=\frac{a+\gamma e+2 \xi e^{2}-\theta \xi e^{2}}{3-2 \theta}$, and $\bar{w}=\frac{(a+\gamma e)(1+\beta)(2+\theta)+\xi e^{2}\left[4+2 \beta-(1+\beta) \theta^{2}\right]}{6+4 \beta-(1+\beta)\left(\theta+2 \theta^{2}\right)}$.

Proposition 1 shows that there are two thresholds which divide the wholesale price into three intervals, and the retailers have different responses in these three intervals.

\subsection{Manufacturer's decisions}

Given the manufacturer's green level and wholesale price decisions, the retailers' best responses are given in Proposition 1. There are three possible responses, depending on the values of the wholesale price but independent of the green level. Therefore, we can first analyze the optimal wholesale price and then determine the optimal green level. Also, to optimize the wholesale price, we shall first obtain the local maxima of the manufacturer's total profit at each of the three intervals, and then discuss the conditions under which each local maximum can be the global optimal one. For ease of presentation, we define two thresholds regarding $\theta$ and two auxiliary functions regarding $\beta$.

We define $\quad \theta_{1}=\frac{\sqrt{17}-3}{4} \quad$ and $\quad \theta_{2}=\frac{1}{9}\left[-12+(1107-54 \sqrt{238})^{1 / 3}+3(41+\right.$ $\left.2 \sqrt{238})^{1 / 3}\right]$. We also define $\beta_{1}(\theta)=\frac{1}{3-6 \theta+2 \theta^{2}}$ for $\theta \in\left(0, \theta_{1}\right)$, and $\beta_{2}(\theta)=$ $\frac{4+10 \theta+8 \theta^{2}+2 \theta^{3}}{14-7 \theta-12 \theta^{2}-3 \theta^{3}}$ for $\theta \in\left(0, \theta_{2}\right)$. As illustrated in Figure 1, it is easy to show that (i) $\theta_{1}<\theta_{2}$, (ii) both $\beta_{1}(\theta)$ and $\beta_{2}(\theta)$ increase in $\theta$, (iii) $0<\beta_{2}(\theta)<\beta_{1}(\theta)$ for any given $\theta \in$ $\left(0, \theta_{1}\right)$, and (iv) $\beta_{1}\left(\theta_{1}\right)=\beta_{2}\left(\theta_{1}\right)$. Thus, we obtain the manufacturer's optimal decisions as summarized in Proposition 2.

Proposition 2. In the MIGP case, the manufacturer's optimal wholesale price $w^{m}$ is given as 
follows.

$$
w^{m}= \begin{cases}\frac{a+\gamma e^{m}+2 \xi\left(e^{m}\right)^{2}-\theta \xi\left(e^{m}\right)^{2}}{3-2 \theta}, & 0<\theta \leq \theta_{1} \text { and } \beta \geq \beta_{1}(\theta), \\ \frac{\left(a+\gamma e^{m}\right)(3+\theta)+\xi\left(e^{m}\right)^{2}\left(7-4 \theta-3 \theta^{2}\right)}{2\left(5-3 \theta-2 \theta^{2}\right)}, & \theta_{1}<\theta<\theta_{2} \text { and } \beta \geq \beta_{2}(\theta), \\ \frac{(1+\beta)\left(a+\gamma e^{m}\right)+(1+2 \beta)(1-\theta) \xi\left(e^{m}\right)^{2}}{(2+3 \beta)(1-\theta)}, & \text { otherwise; }\end{cases}
$$

where $e^{m}=\frac{\gamma}{2 \xi(1-\theta)}$ is the optimal green level.

Note that in Proposition 2, the three possible optimal wholesale prices correspond to the conditionally optimal retailing prices in the three intervals as stated in Proposition 1. Note also that in the first two cases of the optimal wholesale price, retailer 2 achieves an equity outcome, i.e., $\left(\Pi_{2}^{m}-\pi_{2}^{m}\right)^{+}=0$; while in the third case, retailer 2 suffers disadvantageous inequality, i.e., $\left(\Pi_{2}^{m}-\pi_{2}^{m}\right)^{+}>0$. We depict the three cases in Figure 1. For notational convenience, we denote the three possible values of the optimal wholesale prices in (5) as $w_{i}^{m}, i=1,2,3$, respectively, and it is easy to show that $w_{1}^{m}<w_{2}^{m}<w_{3}^{m}$ (note that $w_{1}^{m}=\underline{w}$ ). We find that, intuitively, when retailer 2's equity aversion parameter is nominal (e.g., $\beta<\beta_{2}\left(\theta_{1}\right)$ ) or the substitute level of the two products is sufficiently high (e.g., $\theta \geq \theta_{2}$ ), the manufacturer may not care much about retailer 2' inequity aversion and, as a result, retailer 2 cannot achieve an equity outcome. Otherwise, the manufacturer will carefully choose the wholesale price to ensure that retailer 2 can attain an equity outcome.

Although the wholesale price is a piecewise function with three subdomains, the optimal green level turns out to be unique. This is because in the MIGP case, the investment cost is associated with each unit of products. From Propositions 1 and 2, we can further identify the retailers' optimal retailing prices and the supply chain members' optimal profit. The optimal retailing price can be obtained directly by plugging in $e^{m}$ and $w^{m}$ obtained in Proposition 2 to the best responses in Proposition 1. To avoid redundancy, we present only the supply chain members' profit in the following Table 1.

Table 1 . The supply chain members' profit in the MIGP case.

\begin{tabular}{lll}
\hline $0<\theta \leq \theta_{1}$ & $\theta_{1}<\theta<\theta_{2}$ & otherwise \\
and $\beta \geq \beta_{1}(\theta)$ & and $\beta \geq \beta_{2}(\theta)$ & \\
\hline
\end{tabular}




\begin{tabular}{llll}
\hline$\pi_{1}^{m}$ & $\frac{\delta^{2}}{16\left(3-5 \theta+2 \theta^{2}\right)^{2}}$ & $\frac{\delta^{2}\left(7-\theta-2 \theta^{2}\right)^{2}}{256(1-\theta)^{4}(5+2 \theta)^{2}}$ & $\frac{\delta^{2}\left[2-\theta-\theta^{2}+\beta\left(4-\theta-2 \theta^{2}\right)\right]^{2}}{16(2+3 \beta)^{2}(1-\theta)^{4}\left(4-\theta^{2}\right)^{2}}$ \\
$\pi_{2}^{m}$ & $\frac{\delta^{2}}{16\left(3-5 \theta+2 \theta^{2}\right)^{2}}$ & $\frac{\delta^{2}(3+\theta)[8-\theta(3+\theta)(1+2 \theta)]}{128(1-\theta)^{4}(5+2 \theta)^{2}}$ & $\frac{\delta^{2}\left[2-\theta-\theta^{2}+2 \beta\left(3-\theta-\theta^{2}\right)\right]\left[2-\theta-\theta^{2}+\beta\left(2-2 \theta-\theta^{2}\right)\right]}{16(2+3 \beta)^{2}(1-\theta)^{4}\left(4-\theta^{2}\right)^{2}}$ \\
$\Pi^{m}$ & $\frac{\delta^{2}}{8\left(3-5 \theta+2 \theta^{2}\right)^{2}}$ & $\frac{\delta^{2}(3+\theta)^{2}}{128(1-\theta)^{3}(5+2 \theta)^{2}}$ & $\frac{\delta^{2}(1+\beta)}{16(2+3 \beta)(1-\theta)^{3}(2-\theta)}$ \\
$\Pi_{S c}^{m}$ & $\frac{\delta^{2}}{4\left(3-5 \theta+2 \theta^{2}\right)^{2}}$ & $\frac{\delta^{2}\left[187-10 \theta-\theta^{2}\left(137+52 \theta+4 \theta^{2}\right)\right]}{256(1-\theta)^{4}(5+2 \theta)^{2}}$ & $\frac{\delta^{2}}{16}\left[\frac{(2+6 \beta)(3-2 \theta)}{(2+3 \beta)^{2}(1-\theta)^{3}(2-\theta)^{2}}+\frac{\beta^{2}\left(52-36 \theta-39 \theta^{2}+13 \theta^{3}+9 \theta^{4}\right)}{(2+3 \beta)^{2}(1-\theta)^{4}\left(4-\theta^{2}\right)^{2}}\right]$ \\
\hline
\end{tabular}

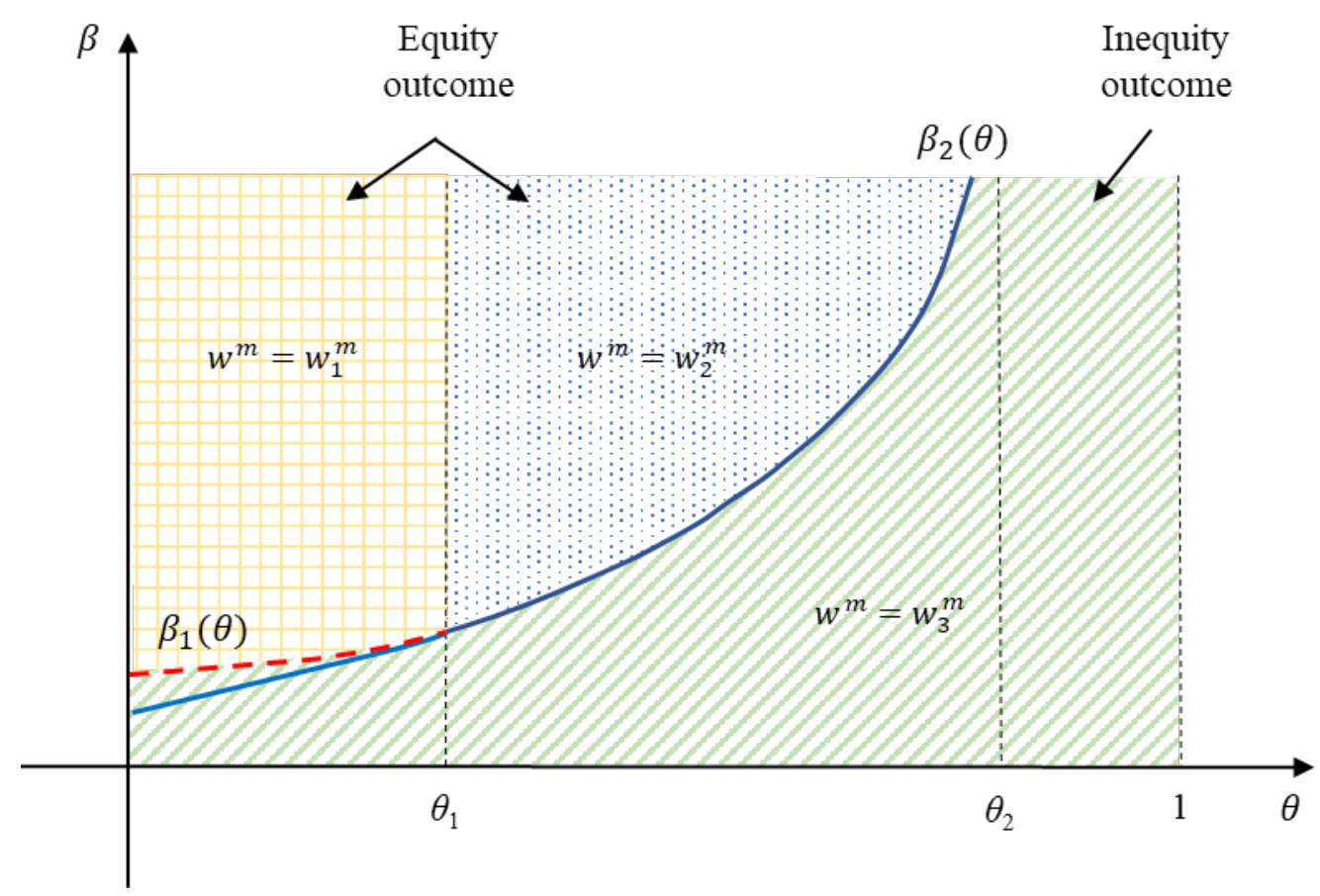

Figure 1. The three possible cases of the optimal wholesale price.

\subsection{Comparison and discussion}

To investigate the impact of retailer 2's distributional inequity aversion on the other supply chain members and the supply chain's performance, we conduct a comparison study in this subsection. We first compare the two retailers' retailing prices and profits according to the results in Table 1 and obtain the following proposition.

Proposition 3: If $0<\theta \leq \theta_{1}$ and $\beta \geq \beta_{1}(\theta)$, then $p_{1}^{m}=p_{2}^{m}$ and $\pi_{1}^{m}=\pi_{2}^{m}$; otherwise, $p_{1}^{m}<p_{2}^{m}, \pi_{1}^{m}>\pi_{2}^{m}$, and $\pi_{1}^{m} / \pi_{2}^{m}$ is non-decreasing in $\theta$ and $\beta$.

In the basic model, the two retailers set identical retailing prices and earn identical profits as revealed in Lemma 1. It is interesting to observe from Proposition 3 that retailer 2's prospect of disadvantageous inequality induces him to set a no smaller retailing price but achieve a no 
higher profit than his horizontal rival. That is, retailer 2's inequity aversion actually harms himself but benefit his competitor. Furthermore, retailer 2's distributional inequity aversion benefits his horizontal competitor more if the substitutability degree of the two products is higher or the inequity aversion sensitivity parameter is higher. If $0<\theta \leq \theta_{1}$ and $\beta \geq \beta_{1}(\theta)$, then the two retailers still set an identical price and earn the same market share, which is higher than that in the basic model, as shown in the following comparison results.

We next compare the optimal solutions and the supply chain members' performance under the cases where retailer 2 has or does not have inequity aversion. Recall that we use the notation “ $"$ to label the optimal solutions in the basic case where all the supply chain members are profit maximizers. Define $\beta_{3}(\theta)=\frac{4 \theta-8+4 \theta^{2}}{6-11 \theta-4 \theta^{2}+\theta^{3}}$ for $\theta \in\left(\theta_{3}, 1\right)$, where $\theta_{3}$ satisfies “ $\beta_{2}\left(\theta_{3}\right)=\beta_{3}\left(\theta_{3}\right)$." We summarize the comparison results in the following proposition.

Proposition 4. There exist two thresholds $\theta_{4}$ and $\theta_{5}\left(\theta_{4}>\theta_{5}\right)$ such that the following comparison results of the optimal decisions and supply chain members 'performance hold.

\begin{tabular}{|c|c|c|c|c|}
\hline & Manufacturer & Retailer 1 & Retailer 2 & Supply chain \\
\hline $\begin{array}{l}\text { Equity } \\
\text { outcome }\end{array}$ & \multirow{2}{*}{$\begin{aligned} e^{m} & =\hat{e}^{m} \\
w^{m} & <\widehat{w}^{m} \\
\Pi^{m} & <\widehat{\Pi}^{m}\end{aligned}$} & \multirow{2}{*}{$\begin{array}{l}p_{1}^{m}<\hat{p}_{1}^{m} \\
\pi_{1}^{m} \geq \hat{\pi}_{1}^{m}\end{array}$} & $\begin{array}{c}p_{2}^{m}<\hat{p}_{2}^{m} \\
\pi_{2}^{m}>\hat{\pi}_{2}^{m} \text { iff } \theta<\theta_{4}\end{array}$ & $\Pi_{s c}^{m}>\widehat{\Pi}_{s c}^{m}$ iff $\theta<\theta_{5}$ \\
\hline $\begin{array}{c}\text { Inequality } \\
\text { outcome }\end{array}$ & & & $\begin{array}{c}p_{2}^{m}>\hat{p}_{2}^{m} \\
\pi_{2}^{\mathrm{m}}>\hat{\pi}_{2}^{m} \text { iff } \beta<\beta_{3}(\theta)\end{array}$ & $\Pi_{s c}^{m}<\widehat{\Pi}_{s c}^{m}$ \\
\hline
\end{tabular}

In the MIGP case, the green investment cost incurs uniformly in every piece of products and retailer 2 is aware of this cost when making decisions. When retailer 2 has inequity aversion, he has the incentive to raise his retailing price to eliminate his disadvantageous inequality, which will harm the market demand. In response, the manufacturer shall try to increase retailer 2's profit. This can be achieved by either increasing the green level or decreasing the wholesale price. Since the design cost of a MIGP increases proportionally to the product sales, either increasing the green level or decreasing the wholesale price can increase retailer 2's profit portion. Proposition 4 shows that in the MIGP case, the manufacturer retains the green level, lowers the wholesale price, and earn a less profit in response to retailer 2's prospect of disadvantageous inequality.

Note that the same wholesale price is offered to both retailers. In response to the 
manufacturer's lowered wholesale price, retailer 1 also lowers her retailing price. This can help retailer 1 to earn a higher profit by winning a no smaller market share (see Proposition 3).

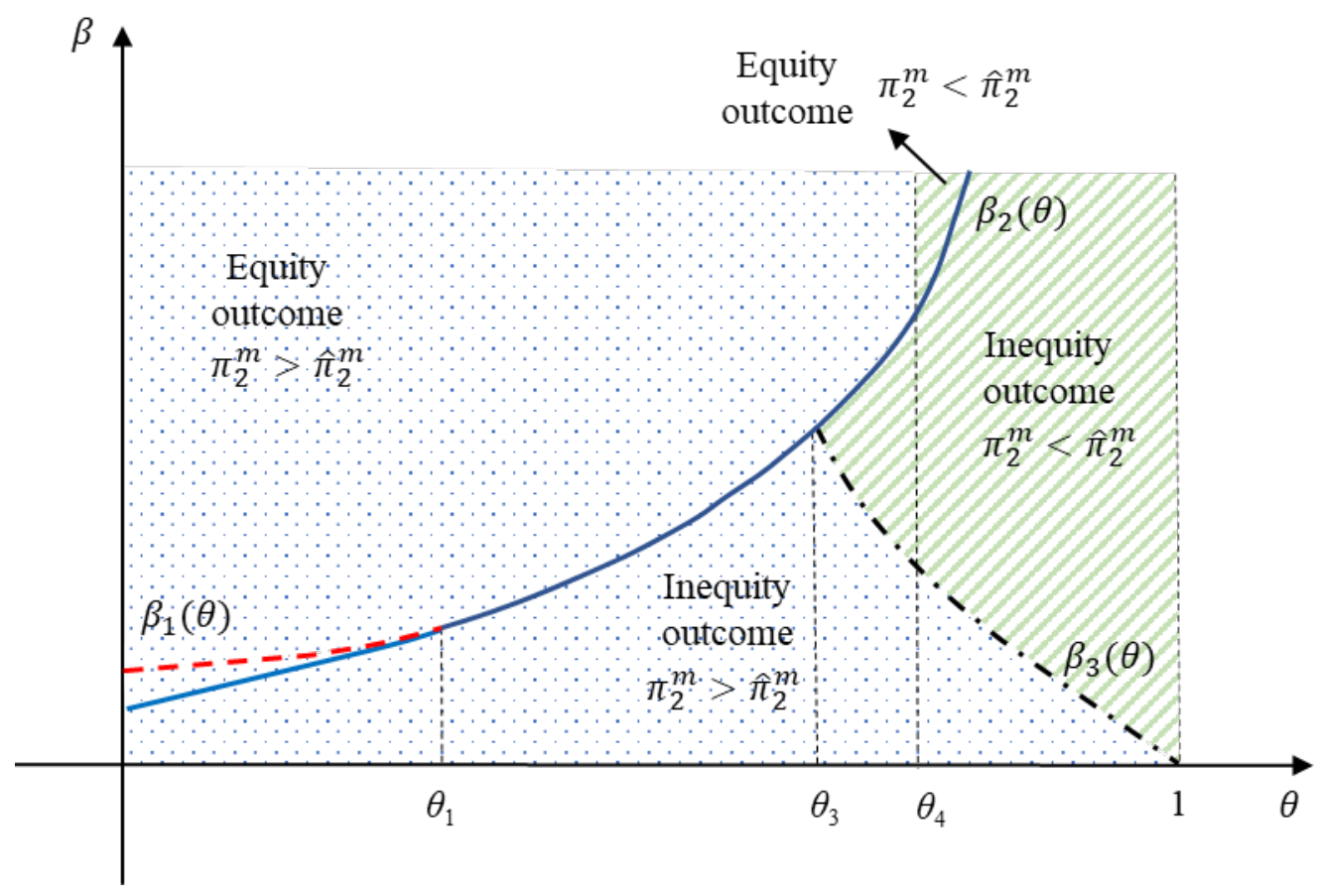

Figure 2. The cases about retailer 2's profit.

Digging deeper, however, retailer 2's optimal retailing price may not necessarily be lower than that in the basic model. Specifically, if retailer 2 can achieve an equity outcome (the regions where $0<\theta \leq \theta_{1}$ and $\beta \geq \beta_{1}(\theta)$, or $\theta_{1}<\theta<\theta_{2}$ and $\beta \geq \beta_{2}(\theta)$ in Figure 1), he will choose a lower retailing price according to manufacturer's wholesale price and achieve a higher profit. However, if retailer 2 attains an inequity outcome, his retailing price is higher than the basic model so as to mitigate the disutility due to disadvantageous inequality. In either case, retailer 2's profit may be higher or lower than that in the basic model.

Note that when retailer 2 achieves an equity outcome, both retailers set lower retailing prices than the basic model. One may think that retailer 2 could also achieve a better profit and double marginalization would be mitigated. This is true for most cases when the equity outcome is attained. However, it is not valid when $\theta$ is sufficiently large (note that when an equity outcome is attained, the value of $\beta$ does not affect the optimal solutions). This is because when the substitutability degree is high, retailer 1 will set a significantly lower retailing price than retailer 2 such that retailer 2 will only earn a small market share. This will harm 
retailer 2 as well as the supply chain. See Figure 2 for illustration.

If retailer 2 cannot achieve an equity outcome, retailer 2 can achieve a higher profit if his inequity aversion sensitivity parameter is not too large. However, the supply chain always has a worse performance than that in the basic model.

\section{The DIGP case}

In this section, we consider the DIGP case in which the total investment cost depends only on the green level and is independent of the production quantity. The key for DIGPs is normally developing new technologies. Follow Zhu and He (2017), we let $\eta e^{2}$ be the total investment

cost given green level $e$, where $\eta>\underline{\eta}=\frac{\gamma^{2}}{4-6 \theta+2 \theta^{2}}$ to avoid trivial cases. With DIGP, the retailers' profit is the same as the case with MIGPs. However, the manufacturer's monetary payoff from trading with retailer $i$ is

$$
\Pi_{i}^{d}=w D_{i}=w\left(a+\gamma e-p_{i}+\theta p_{j}\right)
$$

for $i, j=1,2$ and $i \neq j$, and the manufacturer's total profit is

$$
\Pi^{d}=\Pi_{1}^{d}+\Pi_{2}^{d}-\eta e^{2} .
$$

Similar to Section 4, we first present the results for the basic model where all supply chain members pursue profit maximization with DIGPs.

Lemma 2. For the basic model with DIGPs, the optimal decision variables are

$$
\hat{p}_{i}^{d}=\frac{a \eta(3-2 \theta)}{2 \eta(2-\theta)(1-\theta)-\gamma^{2}}, \quad i=1,2, \quad \widehat{w}^{d}=\frac{a \eta(2-\theta)}{2 \eta(2-\theta)(1-\theta)-\gamma^{2}}, \text { and } \hat{e}^{d}=\frac{\gamma a}{4 \eta-\gamma^{2}-6 \eta \theta+2 \eta \theta^{2}} ;
$$

the supply chain members' profits are

$$
\hat{\pi}_{i}^{d}=\frac{a^{2} \eta^{2}(1-\theta)^{2}}{\left[2 \eta(2-\theta)(1-\theta)-\gamma^{2}\right]^{2}}, \quad i=1,2 \text {, and } \widehat{\Pi}^{d}=\frac{a^{2} \eta}{2 \eta(2-\theta)(1-\theta)-\gamma^{2}} ;
$$

and the total supply chain's profit is $\widehat{\Pi}_{S C}^{d}=\frac{a^{2} \eta\left[2 \eta(1-\theta)(3-2 \theta)-\gamma^{2}\right]}{\left[2 \eta(2-\theta)(1-\theta)-\gamma^{2}\right]^{2}}$.

\subsection{Retailers' and manufacturer's optimal decisions}

In this subsection, we proceed to the model where retailer 2 has inequity aversion. By backwards induction, we first consider the retailers' best responses in the retailing prices to the manufacturer's decisions. With DIGPs, the retailers' objectives are revised as follows. Given the wholesale price $w$ and the green level $e$, retailer 1's monetary payoff profit is the same as the one in the MIGP case, i.e., 


$$
\pi_{1}^{d}=\left(p_{1}-w\right)\left(a+\gamma e-p_{1}+\theta p_{2}\right) ;
$$

However, from (2) and (6), retailer 2's utility becomes

$$
U_{2}^{d}=\left(a+\gamma e-p_{2}+\theta p_{1}\right)\left[\left(p_{2}-w\right)-\beta\left(2 w-p_{2}\right)^{+}\right] .
$$

Note that, compared to $U_{2}^{m}, U_{2}^{d}$ does not include the marginal cost $\xi e^{2}$. Thus, the retailers' best responses in the retailing prices follow directly from Proposition 1 by setting " $\xi=0$." Then, by embedding the best response retailing prices to the manufacturer's profit function, we can derive the manufacturer's optimal decisions by maximizing the profit. Similarly, for a given green level, we first obtain the global optimal wholesale price by comparing the three local optima, and then optimize the green level accordingly. Following the above procedure, we obtain the following proposition.

Proposition 5. In the DIGP case, the manufacturer's optimal wholesale price is

$$
w^{d}= \begin{cases}\frac{a+\gamma e^{d}}{3-2 \theta}, & 0<\theta \leq \theta_{1} \text { and } \beta \geq \beta_{1}(\theta), \\ \frac{(3+\theta)\left(a+\gamma e^{d}\right)}{2(1-\theta)(5+2 \theta)}, & \theta_{1}<\theta<\theta_{2} \text { and } \beta \geq \beta_{2}(\theta), \\ \frac{(1+\beta)\left(a+\gamma e^{d}\right)}{(1-\theta)(2+3 \beta)}, & \text { otherwise; }\end{cases}
$$

where the optimal green level investment $e^{d}$ satisfies

$$
e^{d}= \begin{cases}\frac{2 a \gamma}{\eta(3-2 \theta)^{2}-2 \gamma^{2}}, & 0<\theta \leq \theta_{1} \text { and } \beta \geq \beta_{1}(\theta), \\ \frac{a \gamma(3+\theta)^{2}}{8 \eta(1-\theta)(5+2 \theta)-\gamma^{2}(3+\theta)^{2}}, & \theta_{1}<\theta<\theta_{2} \text { and } \beta \geq \beta_{2}(\theta), \\ \frac{a(1+\beta) \gamma}{\eta(2+3 \beta)(2-\theta)(1-\theta)-(1+\beta) \gamma^{2}}, & \text { otherwise. }\end{cases}
$$

Recall that the optimal green level has a unique value in the MIGP case (as shown in Proposition 2). However, Proposition 5 reveals that, in the DIGP case, the optimal green level investment is a piecewise function with three subdomains corresponding to the three possible optimal wholesale prices. This is because the green level investment cost is a total amount of $\eta e^{2}$, which appears in the manufacturer's total profit function (7). Also, in the first two cases of (9), retailer 2 achieves an equity outcome, and in the last case of (9), retailer 2 suffers disadvantageous inequality. The pattern is identical to that in Figure 1.

Using the optimal decision in Proposition 5, we obtain the supply chain members' profit and the supply chain's total profit as shown in Table 2. 
Table 2. The optimal supply chain members' profits in the DIGP case.

\begin{tabular}{llll}
\hline & $0<\theta \leq \theta_{1}$ & $\theta_{1}<\theta<\theta_{2}$ & otherwise \\
& and $\beta \geq \beta_{1}(\theta)$ & and $\beta \geq \beta_{2}(\theta)$ & $\frac{a^{2} \eta^{2}\left[2-\theta-\theta^{2}+\beta\left(4-\theta-2 \theta^{2}\right)\right]^{2}}{\left[(2+3 \beta)(2-\theta)(1-\theta) \eta-(1+\beta) \gamma^{2}\right]^{2}(2+\theta)^{2}}$ \\
$\pi_{1}^{d}$ & $\frac{a^{2} \eta^{2}(3-2 \theta)^{2}}{\left[\eta(3-2 \theta)^{2}-2 \gamma^{2}\right]^{2}}$ & $\frac{4 a^{2} \eta^{2}\left(7-\theta-2 \theta^{2}\right)^{2}}{\left[8 \eta(1+\theta)(5+2 \theta)-\gamma^{2}(3+\theta)^{2}\right]^{2}}$ & $\frac{a^{2} \eta^{2}\left[2-\theta-\theta^{2}+2 \beta\left(3-\theta-\theta^{2}\right)\right]\left[2-\theta-\theta^{2}+\beta\left(2-2 \theta-\theta^{2}\right)\right]}{\left[(2+3 \beta)(2-\theta)(1-\theta) \eta-(1+\beta) \gamma^{2}\right]^{2}(2+\theta)^{2}}$ \\
$\pi_{2}^{d}$ & $\frac{a^{2} \eta^{2}(3-2 \theta)^{2}}{\left[\eta(3-2 \theta)^{2}-2 \gamma^{2}\right]^{2}}$ & $\frac{8 a^{2} \eta^{2}(3+\theta)[8-\theta(3+\theta)(1+2 \theta)]}{\left[8 \eta(1-\theta)(5+2 \theta)-\gamma^{2}(3+\theta)^{2}\right]^{2}}$ & $\frac{a^{2}(1+\beta) \eta}{(2+3 \beta)(2-\theta)(1-\theta) \eta-(1+\beta) \gamma^{2}}$ \\
$\Pi^{d}$ & $\frac{2 a^{2} \eta}{\eta(3-2 \theta)^{2}-2 \gamma^{2}}$ & $\frac{a^{2} \eta(3+\theta)^{2}}{8 \eta(1-\theta)(5+2 \theta)-\gamma^{2}(3+\theta)^{2}}$ & $\frac{a^{2} \eta\left[\eta(1-\theta)(2+\theta)^{2}(3-2 \theta)(2+6 \beta)+\beta^{2} \eta\left(52-36 \theta-39 \theta^{2}+13 \theta^{3}+9 \theta^{4}\right)-\gamma^{2}(1+\beta)^{2}(2+\theta)^{2}\right]}{\left[(2+3 \beta)(2-\theta)(1-\theta) \eta-(1+\beta) \gamma^{2}\right]^{2}(2+\theta)^{2}}$ \\
$\Pi_{S C}^{d}$ & $\frac{4 a^{2} \eta\left[\eta(3-2 \theta)^{2}-\gamma^{2}\right]}{\left[\eta(3-2 \theta)^{2}-2 \gamma^{2}\right]^{2}}$ & $\frac{a^{2} \eta\left[4 \eta\left(187-10 \theta-137 \theta^{2}-52 \theta^{3}-4 \theta^{4}\right)-\gamma^{2}(3+\theta)^{4}\right]}{\left[8 \eta(1-\theta)(5+2 \theta)-\gamma^{2}(3+\theta)^{2}\right]^{2}}$ & \\
\hline
\end{tabular}

\subsection{Comparison}

In this section, we conduct the comparison study between the models with and without fairness concern for DIGPs. First, similar to the MIGP case, we find that if retailer 2' prospect of disadvantageous inequality matters, then he will earn a less market share than his horizontal competitor. The higher the substitutability degree/disadvantageous inequality sensitive parameter is, the less profit retailer 2 earns relative to retailer 1 . The above results are summarized in Proposition 6.

Proposition 6: If $0<\theta \leq \theta_{1}$ and $\beta \geq \beta_{1}(\theta)$, then $p_{1}^{d}=p_{2}^{d}$ and $\pi_{1}^{d}=\pi_{2}^{d}$; otherwise, $p_{1}^{d}<p_{2}^{d}, \pi_{1}^{d}>\pi_{2}^{d}$, and $\pi_{1}^{d} / \pi_{2}^{d}$ is non-decreasing in $\theta$ and $\beta$.

Next, we compare the supply chain members' performance in the DIGP case (Table 2) with those in the basic model (Lemma 2) and present the results in Proposition 7.

Proposition 7. The comparison of the optimal decisions and supply chain members' performance with and without fairness concerns is summarized as follows.

\begin{tabular}{|c|c|c|c|c|}
\hline & Manufacturer & Retailer 1 & Retailer 2 & Supply chain \\
\hline $\begin{array}{c}\text { Equity } \\
\text { outcome }\end{array}$ & \multirow{2}{*}{$\begin{aligned} e^{d} & <\hat{e}^{d} \\
w^{d} & <\widehat{w}^{d} \\
\Pi^{d} & <\widehat{\Pi}^{d}\end{aligned}$} & \multirow[b]{2}{*}{$p_{1}^{d}<\hat{p}_{1}^{d}$} & $p_{2}^{d}<\hat{p}_{2}^{d}$ & -- \\
\hline $\begin{array}{c}\text { Inequality } \\
\text { outcome }\end{array}$ & & & $\begin{array}{c}p_{2}^{d}>\hat{p}_{2}^{d} \text { iff } \eta> \\
\frac{\gamma^{2}\left(4-\theta-\theta^{2}\right)}{(2-\theta)^{2}(1-\theta)}\end{array}$ & $\Pi_{s c}^{d}<\widehat{\Pi}_{s c}^{d}$ \\
\hline
\end{tabular}

In the DIGP case, in response to retailer 2's inequity aversion, the manufacturer lowers 
the wholesale price, i.e., $w^{d}<\widehat{w}^{d}$, and scarifies some profit, i.e., $\Pi^{d}<\widehat{\Pi}^{d}$, as in the MIGP case. However, the manufacturer also lowers the green level. This is because, in the DIGP case, the manufacturer bears all the investment cost but retailer 2 does not take it into consideration when he evaluates his disadvantageous inequality as implied by (7) - (8). Therefore, unlike the MIGP case, the manufacturer cannot retain the green level in the basic model.

In response to the manufacturer's lowered wholesale price and green level, retailer 1 also lower her retailing price, i.e., $p_{1}^{d}<\hat{p}_{1}^{d}$. However, retailer 1's profit may either increase or decrease. That is, retailer 1 does not necessarily enjoy a profit premium from retailer 2' emotional concern as in the MIGP case.

Compared with the basic model, retailer 2 may either lower or raise his retailing price. Specifically, if retailer 2 does not achieve an equity outcome and the manufacturer's marginal green level investment cost is high, then retailer 2 will raise his retailing price. This is because, as shown in Proposition 5, the green level decreases and the realized market demand decreases when $\eta$ increases. Considering that retailer 2 faces disadvantageous inequality and a shrunk demand, he is eager to increase profit by setting a higher retailing price.

Regarding the supply chain's profit, the supply chain may benefit or be harmed from the fairness concern, depending on $\beta, \theta$, and $\eta$. However, similar to the MIGP case, when retailer 2 cannot achieve an equity outcome, the supply chain cannot achieve the total profit in the basic model (i.e., $\Pi_{s c}^{d}<\widehat{\Pi}_{s c}^{d}$ ).

\section{Conclusion}

In a circular economy, products are designed to be waste-free and negative externality is designed out. In this paper, we examine the green product design in a supply chain with one manufacturer and two competing retailers, where retailer 2 has emotional fairness concerns. According to the types of the green products, we discuss both MIGP and DIGP cases. In each case, we derive the supply chain members' optimal solutions and profits. We also compare the supply chain members' performances with those in the basic models where everyone aims at profit maximization. The effects of retailer 2's fairness concern on his horizontal competitor, on the upstream manufacturer, and on the supply chain performance are obtained. The following results and managerial insights are derived. 
- In the MIGP case, compared to the basic model without fairness concern, the manufacturer retains the green level but lowers the wholesale price when retailer 2 has fairness concern. In the DIMG case, however, the manufacturer lowers both the wholesale price and the green level. In both cases, the manufacturer will sacrifice some profit in response to retailer 2's fairness concern.

- In both cases, compared to the basic model without fairness concern, the fair-minded retailer 2 sets a higher retailing price but earns a less profit than his horizontal competitor. Retailer 2's profit relative to retailer 1's profit decreases due to his emotional inequity concern, and it becomes even worse if the substitutability degree of the products is higher or the inequity aversion sensitivity level is higher.

- Retailer 2' fairness concern benefits his horizontal competitor in the MIGP case, but not necessarily in the DIGP case. In both cases, retailer 2 may earn a higher or a lower profit than the basic models, depending on the substitutability degree and the inequity aversion sensitivity parameter.

- In both cases, the supply chain performs worse if retailer 2 cannot achieve an equity outcome. While retailer 2 achieves an equity outcome, the supply chain can achieve a better performance.

One limitation of this paper is that we only examine the case in which retailer 2 has a distributional fairness concern, and we do not consider the peer-induced fairness concern between the two retailers. Investigating of the joint effects of distributional and peer-induced fairness concerns, with allowing various wholesale prices, can be a possible future work on this topic. Second, we do not consider carbon emission reduction as a result of green investment. Modeling carbon emission cost and environmental taxes to the current setting is another future research direction (e.g., Choi 2013, Choi and Chiu 2012). Third, in this paper we consider a deterministic investment model in a symmetric information setting. Possible model extensions are to investigate the effects of demand uncertainty (e.g., Dong et al. 2016, Chan et al. 2018), and information asymmetry (e.g., Li and Zhou 2019, Zhang et al. 2018) in addition to the framework discussed in this paper. 
We thank the $\mathrm{AE}$ and the three reviewers for their constructive comments. This research was supported in part by the National Natural Science Foundation of China under the grant no. 71871052, 71501037, 71832001, the Fundamental Research Funds for the Central Universities and DHU Distinguished Young Professor Program, and SJSU Central RSCA Grant. This work was also supported by the NSFC/RGC Joint Research Scheme (Grant numbers 3-RAA7, $71661167009)$.

\section{References}

Alzaman, C. (2014). Green supply chain modelling: literature review. International Journal of Business Performance and Supply Chain Modelling, 6(1), 16-39.

Caliskan-Demirag, O., Chen, Y. F., \& Li, J. (2010). Channel coordination under fairness concerns and nonlinear demand. European Journal of Operational Research, 207(3), 1321-1326.

Centobelli, P., Cerchione, R., \& Esposito, E. (2018). Environmental sustainability and energy-efficient supply chain management: A review of research trends and proposed guidelines. Energies, 11(2), 275.

Chan, H. L., Choi, T. M., Cai, Y. J., \& Shen, B. (2018). Environmental Taxes in Newsvendor Supply Chains: A Mean-Downside-Risk Analysis. IEEE Transactions on Systems, Man, and Cybernetics: Systems.

Chen, X., Wang, X., \& Chan, H. K. (2017a). Manufacturer and retailer coordination for environmental and economic competitiveness: A power perspective. Transportation Research Part E: Logistics and Transportation Review, 97, 268-281.

Chen, J., Zhao, X., \& Shen, Z. J. (2015). Risk mitigation benefit from backup suppliers in the presence of the horizontal fairness concern. Decision Sciences, 46(4), 663-696.

Chen, J., Zhou, Y. W., \& Zhong, Y. (2017b). A pricing/ordering model for a dyadic supply chain with buyback guarantee financing and fairness concerns. International Journal of Production Research, 55(18), 5287-5304.

Choi, T. M. (2013). Optimal apparel supplier selection with forecast updates under carbon emission taxation scheme. Computers \& Operations Research, 40(11), 2646-2655.

Choi, T. M., \& Chiu, C. H. (2012). Mean-downside-risk and mean-variance newsvendor models: Implications for sustainable fashion retailing. International Journal of Production Economics, 135(2), $552-560$.

Cui, H.T., Raju, J.S., \& Zhang, Z.J. (2007). Fairness and channel coordination. Management Science, $53(8), 1303-1314$. 
Dey, K., Roy, S., \& Saha, S. (2019). The impact of strategic inventory and procurement strategies on green product design in a two-period supply chain. International Journal of Production Research, 57(7), 1915-1948.

Dong, C., Shen, B., Chow, P. S., Yang, L., \& Ng, C. T. (2016). Sustainability investment under capand-trade regulation. Annals of Operations Research, 240(2), 509-531.

Du, B., Liu, Q., \& Li, G. (2017). Coordinating leader-follower supply chain with sustainable green technology innovation on their fairness concerns. International Journal of Environmental Research and Public Health, 14(11), 1357.

Du, S., Nie, T., Chu, C., \& Yu, Y. (2014). Newsvendor model for a dyadic supply chain with Nash bargaining fairness concerns. International Journal of Production Research, 52(17), 5070-5085.

Du, S., Wei, L., Zhu, Y., \& Nie, T. (2018). Peer-regarding fairness in supply chain. International Journal of Production Research, 56(10), 3384-3396.

Ellen MacArthur Foundation (2015). Towards a circular economy: business rationale for an accelerated transition. https://www.ellenmacarthurfoundation.org/assets/downloads/TCE_Ellen-MacArthurFoundation_9-Dec-2015.pdf

EU ETS (2017). Directive (EU) 2018/410 of the European Parliament and of the Council of 14 March 2018 amending Directive 2003/87/EC to enhance cost-effective emission reductions and low-carbon investments, and Decision (EU). Official Journal of the European Union: Legislation, 76, 3-27.

Eurobarometer (2009). Europeans' attitudes towards the issue of sustainable consumption and production. Flash Eurobarometer Report, 256.

Fehr, E., \& Schmidt, K. M. (1999). A theory of fairness, competition, and cooperation. The Quarterly Journal of Economics, 114(3), 817-868.

Ghosh, D., \& Shah, J. (2012). A comparative analysis of greening policies across supply chain structures. International Journal of Production Economics, 135(2), 568-583.

Ghosh, D., \& Shah, J. (2015). Supply chain analysis under green sensitive consumer demand and cost sharing contract. International Journal of Production Economics, 164, 319-329.

Giri, R. N., Mondal, S. K., \& Maiti, M. (2019). Government intervention on a competing supply chain with two green manufacturers and a retailer. Computers \& Industrial Engineering, 128, 104-121.

Gleim, M. R., Smith, J. S., Andrews, D., \& Cronin Jr, J. J. (2013). Against the green: a multi-method examination of the barriers to green consumption. Journal of Retailing, 89(1), 44-61.

Govindan, K., \& Hasanagic, M. (2018). A systematic review on drivers, barriers, and practices towards circular economy: a supply chain perspective. International Journal of Production Research, 56(1-2), 278-311.

Ho, T. H., Su, X., \& Wu, Y. (2014). Distributional and peer-induced fairness in supply chain contract design. Production and Operations Management, 23(2), 161-175.

Hong, Z., Wang, H., \& Gong, Y. (2019). Green product design considering functional-product reference. International Journal of Production Economics, 210, 155-168. 
Katok, E., Olsen, T., \& Pavlov, V. (2014). Wholesale pricing under mild and privately known concerns for fairness. Production and Operations Management, 23(2), 285-302.

Lacy, P., \& Rutqvist, J. (2015). Waste to wealth: The circular economy advantage. Palgrave MacMillan: UK.

Li, Q. (2018). The optimal multi-period modular design with fairness concerns. International Journal of Production Economics, 206, 233-249.

Li, Q., \& Shen, B. (2016). Sustainable Design Operations in the Supply Chain: Non-Profit Manufacturer vs. For-Profit Manufacturer. Sustainability, 8(7), 639.

Li, Q., Xiao, T., \& Qiu, Y. (2018). Price and carbon emission reduction decisions and revenue-sharing contract considering fairness concerns. Journal of Cleaner Production, 190, 303-314.

Li, Q., \& Zhou, J. (2019). A Horizontal Capacity Reservation Game Under Asymmetric Information. International Journal of Production Research, 57(4), 1103-1118.

Li, T., Xie, J., Zhao, X., \& Tang, J. (2016). On supplier encroachment with retailer's fairness concerns. Computers \& Industrial Engineering, 98, 499-512.

Liu, W., Wang, D., Shen, X., Yan, X., \& Wei, W. (2018). The impacts of distributional and peerinduced fairness concerns on the decision-making of order allocation in logistics service supply chain. Transportation Research Part E: Logistics and Transportation Review, 116, 102-122.

Liu, Z. L., Anderson, T. D., \& Cruz, J. M. (2012). Consumer environmental awareness and competition in two-stage supply chains. European Journal of Operational Research, 218(3), 602-613.

Ma, P., Li, K. W., \& Wang, Z. J. (2017). Pricing decisions in closed-loop supply chains with marketing effort and fairness concerns. International Journal of Production Research, 55(22), 6710-6731.

Nie, T., \& Du, S. (2017). Dual-fairness supply chain with quantity discount contracts. European Journal of Operational Research, 258(2), 491-500.

Nielsen, C. (2015). The sustainability imperative: new insights on consumer expectations.

Rabin, M. (1993). Incorporating fairness into game theory and economics. The American economic review, 1281-1302.

Raj, A., Biswas, I., \& Srivastava, S. K. (2018). Designing supply contracts for the sustainable supply chain using game theory. Journal of Cleaner Production, 185, 275-284.

Shi, X., Chan, H. L., \& Dong, C. (2018). Value of bargaining contract in a supply chain system with sustainability investment: An incentive analysis. IEEE Transactions on Systems, Man, and Cybernetics: Systems.

Shi, X., Dong, C., Zhang, C., \& Zhang, X. (2019). Who should invest in clean technologies in a supply chain with competition?. Journal of Cleaner Production.

Sim, J., El Ouardighi, F., \& Kim, B. (2019). Economic and environmental impacts of vertical and horizontal competition and integration. Naval Research Logistics, 66(2), 133-153. 
UN Global Compact \& Accenture (2010). A New Era of Sustainability UN Global Compact-Accenture CEO Study 2010. Available at https://www.unglobalcompact.org/library/230.

Walmart (2019). Walmart announces new plastic packaging waste reduction commitments. Available at https://corporate.walmart.com/esgreport/social\#providing-safer-healthier-food-other-products.

Wang, M., Liu, J., Chan, H. L., Choi, T. M., \& Yue, X. (2016). Effects of carbon tariffs trading policy on duopoly market entry decisions and price competition: Insights from textile firms of developing countries. International Journal of Production Economics, 181, 470-484.

Wang, Y., Yu, Z., \& Shen, L. (2019). Study on the decision-making and coordination of an e-commerce supply chain with manufacturer fairness concerns. International Journal of Production Research, 57(9), 2788-2808.

WEEE Directive (2002). Directive 2002/96/EC of the European Parliament and of the Council of 27 January 2003 on waste electrical and electronic equipment. Official Journal of the European Union: Legislation, 197, 38-71.

WEEE Directive (2012). Directive 2012/19/EU of the European Parliament and of the Council of 4 July 2012 on waste electrical and electronic equipment. Official Journal of the European Union: Legislation, $55,45-46$.

Wu, X., \& Niederhoff, J. A. (2014). Fairness in selling to the newsvendor. Production and Operations Management, 23(11), 2002-2022.

Xu, X., He, P., Xu, H., \& Zhang, Q. (2017). Supply chain coordination with green technology under cap-and-trade regulation. International Journal of Production Economics, 183, 433-442.

Yang, J., Xie, J., Deng, X., \& Xiong, H. (2013). Cooperative advertising in a distribution channel with fairness concerns. European Journal of Operational Research, 227(2), 401-407.

Zhang, T., Choi, T. M., \& Zhu, X. (2018). Optimal green product's pricing and level of sustainability in supply chains: effects of information and coordination. Annals of Operations Research, forthcoming.

Zhang, L., Zhou, H., Liu, Y., \& Lu, R. (2019). Optimal environmental quality and price with consumer environmental awareness and retailer's fairness concerns in supply chain. Journal of Cleaner Production, 213, 1063-1079.

Zhang, T., \& Wang, X. (2018). The impact of fairness concern on the three-party supply chain coordination. Industrial Marketing Management, 73, 99-115.

Zhu, W., \& He, Y. (2017). Green product design in supply chains under competition. European Journal of Operational Research, 258(1), 165-180. 